\title{
Influence of grand-mother diet on offspring performances through the male line in Muscovy duck
}

Jean-Michel Brun 1,2,3, Marie-Dominique Bernadet ${ }^{4}$, Alexis Cornuez ${ }^{4}$, Sophie Leroux ${ }^{1,2,3}$, Loys Bodin ${ }^{1,2,3}$, Benjamin Basso 1,2,3,8,9, Stéphane Davail ${ }^{5}$, Mathilde Jaglin ${ }^{5}$, Michel Lessire ${ }^{6}$, Xavier Martin $^{4}$, Nadine Sellier ${ }^{7}$, Mireille Morisson ${ }^{1,2,3}$ and Frédérique Pitel ${ }^{1,2,3^{*}}$

\begin{abstract}
Background: In mammals, multigenerational environmental effects have been documented by either epidemiological studies in human or animal experiments in rodents. Whether such phenomena also occur in birds for more than one generation is still an open question. The objective of this study was to investigate if a methionine deficiency experienced by a mother (G0) could affect her grand-offspring phenotypes (G2 hybrid mule ducks and G2 purebred Muscovy ducks), through their Muscovy sons (G1). Muscovy drakes are used for the production of mule ducks, which are sterile offspring of female common duck (Anas platyrhynchos) and Muscovy drakes (Cairina moschata). In France, mule ducks are bred mainly for the production of "foie gras", which stems from hepatic steatosis under two weeks of force-feeding (FF). Two groups of female Muscovy ducks received either a methionine deficient diet or a control diet. Their sons were mated to Muscovy or to common duck females to produce Muscovy or Mule ducks, respectively. Several traits were measured in the G2 progenies, concerning growth, feed efficiency during FF, body composition after FF, and quality of foie gras and magret.
\end{abstract}

Results: In the G2 mule duck progeny, grand-maternal methionine deficiency (GMMD) decreased 4, 8, and 12 week body weights but increased weight gain and feed efficiency during FF, and abdominal fat weight. The plasmatic glucose and triglyceride contents at the end of FF were higher in the methionine deficient group. In the G2 purebred Muscovy progeny, GMMD tended to decrease 4 week body weight in both sexes, and decreased weight gain between the ages of 4 and 12 weeks, 12 week body weight, and body weight at the end of FF in male offspring only. GMMD tended to increase liver weight and increased the carcass proportion of liver in both sexes.

Conclusion: Altogether, these results show that the mother's diet is able to affect traits linked to growth and to lipid metabolism in the offspring of her sons, in Muscovy ducks. Whether this transmission through the father of information induced in the grand-mother by the environment is epigenetic remains to be demonstrated.

Keywords: Environment, Diet, Methionine, Duck, Multigenerational, Epigenetics

\footnotetext{
* Correspondence: frederique.pitel@toulouse.inra.fr

'UMR INRA, Génétique, Physiologie et Systèmes d'Elevage, INRA, 31328

Castanet Tolosan, France

2INPT ENSAT, Génétique, Physiologie et Systèmes d'Elevage, INRA, 31328

Castanet Tolosan, France

Full list of author information is available at the end of the article
} 


\section{Background}

In animal breeding, maternal and even grand-maternal effects, in addition to the direct effects of the genes transmitted to the offspring, have been postulated, modelled and estimated for a long time [1,2]. The mother contributes to the offspring phenotype through the genes she passed on to the next generation, but also through maternal effects, independent from the genes the offspring has received from his mother. The renewed interest epigenetics has acquired in biological sciences in the past few decades has in many cases given a biological basis to non-genetic multigenerational effects $[3,4]$. However, while multigenerational effects of maternal environment are well recognized, whether epigenetic or not, those of paternal environment are more rarely considered, even though they more certainly represent epigenetic phenomena, or "transgenerational inheritance". Over one generation, several animal and epidemiological studies on various nutrition and lifestyle related conditions have reported an effect of the paternal environment on the offspring phenotype (premating fasting of male mice [5]; high fat diet in male rats [6]; see $[7,8]$ for a review). Non-genetic effects involving the male germ-line have also been documented by either epidemiological studies in human such as the prenatal exposure of fathers to the Dutch famine [9], exposure of paternal grand-fathers $[10,11]$ or grandmothers [12] to different food supplies in Sweden, or animal experiments such as the effects of endocrine disruptors on male fertility in the rat [13]. Whether these phenomena also occur in birds has not been investigated yet [14].

The objective of this study was thus to investigate non-genetic multigenerational effects induced by the environment in duck, the environment effector being here a dietary methyl-donor deficiency. In France, mule ducks, which are hybrids of common female ducks (Anas platyrhynchos) and Muscovy drakes (Cairina moschata) are bred for the production of "foie gras" and of "magrets", the pectoral muscle (with skin) of force fed ducks. Force-feeding leads to a hepatic steatosis, with a tenfold increase in liver weight within two weeks, from 12 to 14 weeks of age. The idea of investigating multigenerational effects in the duck stemmed from a parallel between steatosis in duck and obesity in human and in mice, which is often associated to multigenerational effects and to epigenetic mechanisms ([7, 15], see [16] for a review). A methyl-donor limitation was applied to the Muscovy dams (G0) before and during the conception of their sons (G1), through a methionine restriction of the diet. The multigenerational effects were evaluated on G2, either purebred Muscovy ducks or hybrid mule ducks issued from these G1 sires.

\section{Methods}

All procedures were conducted in accordance with guidelines for Care and Use of Animals in Agricultural Research and Teaching (French Agricultural Agency and Scientific Research Agency; approval number of the experimental farm: B40-037-1; Ethics committee approval $\mathrm{n}^{\circ} 00066.03$ from the C2EA-73 “Comité d'Ethique Aquitaine Poissons Oiseaux").

\section{Animals and experimental design}

The experiment was conducted at the INRA UEPFG experimental farm for waterfowl (Benquet, France) between 2010 and 2013, and involved three generations of animals, G0, G1, and G2 (Fig. 1).

In G0, 8 Muscovy female ducks of the R71M strain were purchased (Grimaud Frères S.A.), raised at UEPFG and allocated to two diet groups when placed in individual reproduction cages at the age of 10 weeks until the age of 35 weeks. Both groups were fed a growing diet until 17 weeks of age, followed by a reproduction diet until the end of breeding. Females of the first group $(n=4)$ were fed a Met-deficient diet. The other four females were fed a control diet. The nutritional characteristics of the growing and reproduction diets, which were produced at the INRA PEAT experimental mill (Nouzilly, France) are given in Table 1. The growing and the reproduction diets were produced from the same base, but the Met contents was $2.6 \mathrm{~g} / \mathrm{kg}$ for the Met-deficient diet and $4.2 \mathrm{~g} / \mathrm{kg}$ for the control diet, the latest being in conformity with the recommendations. The diets were given as pellets.

At the age of 25 to 26 weeks the females were inseminated with semen of Muscovy drakes of the INRA66 strain in order to produce G1 drakes. Each drake inseminated two Met-deficient and two control females. A total of $25 \mathrm{G1}$ ducks of both sexes were raised, of which eight males were kept for reproduction, four from each diet group of the G0 dams. The G1 males were from three different mothers in each group. The procreation of the G2 mule ducks was performed by artificially inseminating the semen of G1 Muscovy drakes to common duck females of the INRA444 strain. Two batches were produced (2012 and 2013). The procreation of G2 purebred Muscovy ducks was performed by artificially inseminating the semen of G1 Muscovy drakes to Muscovy females of the INRA66 strain. Only one batch was produced (2013). A mating plan was designed and controlled at each generation: the inseminations were performed following a nested mating design: the semen from each male was used for inseminating its own mates.

The G2 mule ducks and Muscovy ducks were fed ad libitum a commercial starting diet from 0 to 4 weeks of age, followed by a commercial growing diet until 12 weeks of age. From the age of 8 weeks until 12 weeks, 
G0

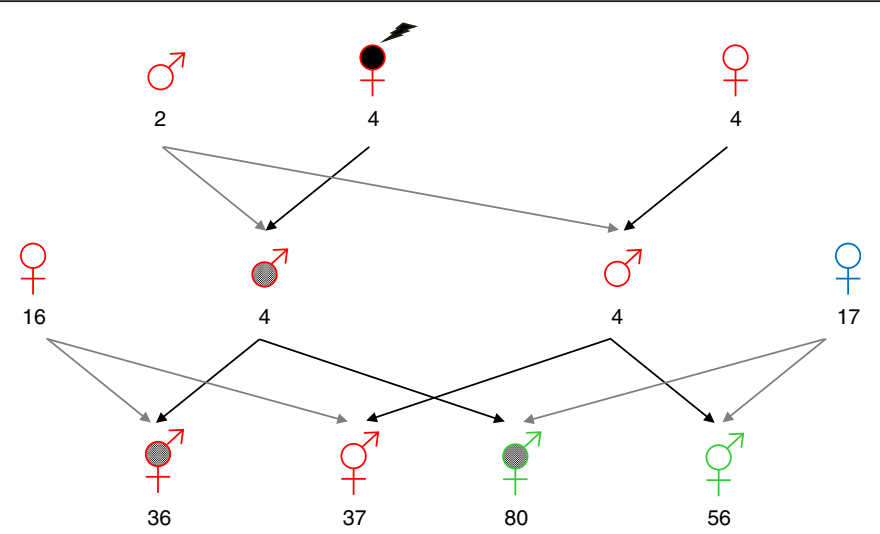

Fig. 1 Experimental design. In G0, four females were fed a Met-deficient diet while four other females were fed a control diet. They were inseminated with semen of two Muscovy drakes in order to produce G1 drakes. A total of 25 G1 ducks of both sexes were raised, of which eight males were kept for reproduction, four from each diet group of the $\mathrm{G} 0$ dams. The procreation of the $\mathrm{G} 2$ mule ducks was performed by artificial insemination with the semen of G1 Muscovy drakes to common duck females. The procreation of G2 purebred Muscovy ducks was performed by artificially inseminating the semen of G1 Muscovy drakes to Muscovy females. Black: with Met-deficient diet, hatched: having an ancestor with Met-deficient diet, red: Muscovy duck, blue: Common duck, green: Mule duck. The number of individuals in each group is indicated

Table 1 Composition of the Met-deficient diets ${ }^{1}$ of the G0 female Muscovy duck

\begin{tabular}{lll}
\hline & $\begin{array}{l}\text { Growing } \\
\text { diet(9-15 weeks) }\end{array}$ & $\begin{array}{l}\text { Reproduction } \\
\text { diet(beyond 15 weeks) }\end{array}$ \\
\hline Ingredients g/kg & 501 & 461.8 \\
Maize & 196.3 & 222.3 \\
Soybean meal & 200 & 200 \\
Wheat & 53.3 & 26.8 \\
Wheat bran & 20 & 10 \\
Soybean oil & 13.4 & 16.8 \\
Phosphate Dicalcium & 7.78 & 54.8 \\
Limestone & 5 & 4 \\
Trace elements & 3 & 3 \\
NaCl & 0.22 & 0.5 \\
Lys Hcl & 2900 & \\
Expected nutritional composition & 2700 \\
Metabolisable Energy, & 29.5 \\
Kcal/kg & & \\
Protein, g/kg & 160 & 165 \\
Lys, g/kg & 7.8 & 8.5 \\
Met, g/kg & 2.56 & 2.61 \\
Met + Cyst, g/kg & 5.59 & 5.65 \\
Try, g/kg & 1.79 & 1.86 \\
Thr, g/kg & 5.96 & 6.16 \\
Ca, g/kg & 8.55 & 27 \\
P, g/kg & 0.55 & \\
Choline chloride, g/kg & & \\
\hline
\end{tabular}

1DL-Met was added to form the control diet all the G2 ducks underwent preparation for forcefeeding in order to expand their crop by restricting the duration of access to the feeders and making the ducks ingest their ration quickly. They were then force-fed in collective cages of four ducks of the same sex, genetic background and diet groups. Force-feeding (FF) consisted of two meals per day for $13 \mathrm{~d}$ (a total of 25 meals) with a mixture of $35 \%$ maize flour, $25 \%$ maize grain, and $40 \%$ water. A specific FF planning was applied to mule ducks (the same for both sexes), to male Muscovy ducks and to female Muscovy ducks, with a planned total feed quantity at $9685 \mathrm{~g}$ (dry matter), $7265 \mathrm{~g}$ and $5760 \mathrm{~g}$ for the three types, respectively. When the previous meal had not been digested by a duck it was either fed a half-meal or skipped the meal. Slaughter occurred at the end of force-feeding, at 14 weeks of age, in the slaughter room of the experimental farm. The ducks were bled after electronarcosis and plucked. The carcasses were refrigerated for $24 \mathrm{~h}$ at $4{ }^{\circ} \mathrm{C}$, and then eviscerated. Livers and magrets were removed. The magrets were dissected into muscle and skin (including subcutaneous fat). Samples of livers were taken in order to evaluate the technological yield of liver at sterilization, generally denoted by "melting rate" according to the procedure described by [17].

\section{Traits studied}

The focus was put on the G2 mule and Muscovy ducks. However, several traits which could have been affected by the Met restriction were recorded in the G0 and G1 generations. Concerning G0 Muscovy females, laying was recorded all over the laying period. Fertility and hatchability were recorded during the reproduction periods. Concerning G1, male and female offspring were 
weighed at the ages of 24, 43, 65 and 95d. The 8 males retained for reproduction were also weighed at $143 \mathrm{~d}$ of age.

Concerning the G2 mule and Muscovy ducks, body weight at 4, 8, and 12 week of age were measured and the weight gains between consecutive ages were calculated. Individual feed consumption during FF was recorded for each meal and total feed consumption during FF was calculated. Body weight at the end of FF was recorded and weight gain during FF was calculated, along with the ratio (ingested feed/ weight gain) indicating feed efficiency during FF. Carcass was weighed and carcass yield was calculated. Liver weight, the carcass percentage of liver and the melting rate were recorded. Abdominal fat weight and its carcass percentage were evaluated. Magret weight, carcass percentage of magret, and the percentage of 'skin + subcutaneous fat' in the magret, an indicator of overall subcutaneous fatness of the duck, were also recorded. The concentration of two plasma parameters, glucose and triglycerides, was determined from blood samples taken three hours after the meal, at two stages of the FF period: in the middle (after the 12th meal) and at the end (after the 24th meal).

\section{Statistical analyses}

Laying and reproductive output of G0 females were analyzed by analysis of variance (ANOVA) according to the diet. The weights of G1 offspring during growth were analyzed by ANOVA according to the maternal diet, the sex, and an interaction between both factors. Concerning G2, the mule duck traits and the Muscovy duck traits were analyzed separately, because of i) the different time span of both genetic types (two years in mule ducks vs. one year in Muscovy ducks), ii) the specific high sexual dimorphism of body weight in Muscovy ducks and iii) hence, the potentially specific interactions involving year and sex. The mule duck traits were analyzed by ANOVA with the fixed effects of grand-maternal diet, year, sex, and paternal grand-sire (2 levels). In a first step, all 2 by 2 interactions were introduced in the model except those involving the paternal grand-sire. The interactions 'diet by year' and 'diet by sex' were not significant. The model retained was thus a model without interactions for all traits except for liver weight, carcass percentage of liver and liver technological yield, for which a 'year by sex' interaction was included in the model.

The model retained for the analysis of G2 Muscovy ducks included the fixed effect of grand-maternal diet, sex, the paternal grand-sire, and an interaction between grand-maternal diet and sex. In the analyses of the G2 progeny traits, we tried to partition at best what is due to genetic inheritance vs. diet-related parental effects. This could have been achieved by taking into account a dam effect or a full-sib family effect. However, since the design involved dams nested within sires which were themselves nested within the diets,, this would have neither changed the estimate of the diet effect, nor prevented an eventual confounding. Actually, this confounding can be partially removed only through effects which are crossed and not nested with the diet effect. The only genetic effect that was crossed with the diet was the paternal grand-sire of the G2 individuals and it was included in the model.

The ANOVAs were performed using the PROC GLM procedure of SAS (SAS Inst., Cary, NC, USA).

\section{Results}

\section{Zootechnical results at G0 and G1 generations}

Met deficiency showed no significant effects on laying rate, fertility or hatchability.

Maternal diet had no significant effect on the weights of G1 progeny at any age and there was no significant diet by sex interaction. The eight males (four Met-deficient and four Control) which were utilized as breeders to procreate the G2 offspring showed no significant weight differences between diets. Their 143 d-body weight was, on average, $4244 \pm 109 \mathrm{~g}$ for the Met deficient diet and $4182 \pm 109 \mathrm{~g}$ for the control diet.

\section{Effects of grand-maternal Met-deficiency (GMMD) on G2 mule ducks}

Table 2 gives descriptive statistics of the G2 mule duck traits, the statistical significance of the factors of the ANOVA and the least square means of the G2 mule duck traits, according to grand-maternal diet, for traits showing significant diet effects in this progeny type. For comparison purposes between both progeny types, means are also given for the traits showing a significant diet effect in the Muscovy progeny. In the following text, G2 ducks with a Met-deficient grand-mother will be referred to as GMMD ducks.

GMMD had a significant effect $(P<0.05)$ on 4,8 , and 12 week body weights of mule ducks, decreasing body weight by $5 \%, 3.4 \%$, and $2 \%$ at these three ages, respectively. This effect was no longer observed after FF, at the age of 14 weeks (it even showed the reverse trend) because weight gain during FF was significantly higher for GMMD mule ducks $(P<0.01$, Fig. 2$)$.

Feed consumption during FF was not different between the two diet groups, indicating that they had the same ability to ingest the standardized FF doses. Consequently, feed efficiency during FF was higher in the GMMD group $(P<0.001)$.

Abdominal fat deposits were higher in the GMMD group $(P<0.05)$, as absolute value and as percentage of the carcass.

The plasmatic triglyceride content showed a significant effect of GMMD at the end of FF, but no effect at 
Table 2 Results obtained on G2 mule duck traits. Statistical significance of the effects of grand-maternal (GM) diet, year, sex and year by sex interaction on G2 mule duck traits (paternal grand-sire effect is not given), and least square means ( \pm SE) of GM diet ${ }^{a}$

\begin{tabular}{|c|c|c|c|c|c|c|c|}
\hline & $\mathrm{N}$ & GM diet & Year & Sex & Year $x$ sex & Met-deficient & Control \\
\hline \multicolumn{8}{|l|}{ Growth traits } \\
\hline Body weight, 4 weeks & 133 & $* * *$ & ns & $* * *$ & - & $1326 \pm 10^{d}$ & $1397 \pm 11^{c}$ \\
\hline Body weight, 8 weeks & 134 & $* * *$ & $* * *$ & $* * *$ & - & $2814 \pm 19^{d}$ & $2913 \pm 21^{c}$ \\
\hline Body weight, 12 weeks & 133 & * & $* * *$ & Ns & - & $3390 \pm 23^{d}$ & $3458 \pm 25^{c}$ \\
\hline Weight gain, 4-8weeks & 133 & ns & $* * *$ & ns & - & & \\
\hline Weight gain, 8-12weeks & 133 & ns & ns & $* * *$ & - & $577 \pm 19$ & $545 \pm 21$ \\
\hline Weight gain, 4-12weeks & 132 & ns & $* * *$ & $* * *$ & - & & \\
\hline \multicolumn{8}{|l|}{ Force-feeding (FF) traits } \\
\hline Weight gain during FF & 130 & $* *$ & ns & $* * *$ & - & $1609 \pm 23^{c}$ & $1502 \pm 25^{d}$ \\
\hline Body weight, 14 weeks (end FF) & 131 & ns & $* *$ & $* * *$ & - & $5016 \pm 30$ & $4960 \pm 33$ \\
\hline Feed consumption during FF & 131 & ns & $* * *$ & $* * *$ & - & $14071 \pm 48$ & $14026 \pm 53$ \\
\hline Ratio FCMG during FF & 129 & $* * *$ & ns & $* * *$ & - & $8.78 \pm 0.15^{c}$ & $9.58 \pm 0.17^{d}$ \\
\hline \multicolumn{8}{|l|}{ Carcass traits } \\
\hline Carcass weight (CW) & 129 & ns & * & $* * *$ & - & & \\
\hline Magret $^{b}$ weight & 131 & ns & ns & * & - & $367.1 \pm 3.4$ & $364.5 \pm 3.7$ \\
\hline Ratio (magret/carcass) & 128 & ns & * & ns & - & & \\
\hline Magret muscle weight & 131 & ns & ns & ns & - & & \\
\hline Ratio (fat + skin/magret) & 131 & ns & ns & ns & - & & \\
\hline Abdominal fat weight (AF) & 131 & * & ns & $* *$ & - & $156.7 \pm 2.7^{c}$ & $146.5 \pm 2.9^{d}$ \\
\hline Ratio AF/CW \% & 128 & * & ns & ns & - & $3.45 \pm 0.05^{c}$ & $3.27 \pm 0.06^{\mathrm{d}}$ \\
\hline Liver weight (LW) & 131 & ns & ns & ns & $* * *$ & & \\
\hline Ratio (LW/CW) & 128 & ns & ns & $* *$ & $* *$ & $12.1 \pm 0.3$ & $11.9 \pm 0.3$ \\
\hline Liver melting rate & 131 & ns & $* * *$ & $* * *$ & $* *$ & & \\
\hline \multicolumn{8}{|l|}{ Blood metabolites } \\
\hline Glucose mid-FF (g/L) & 129 & ns & ns & $* *$ & - & & \\
\hline Glucose end-FF (g/L) & 105 & + & ns & $* * *$ & - & $3.27 \pm 0.19$ & $2.83 \pm 0.20$ \\
\hline Triglycerides mid-FF ( $g / L)$ & 129 & ns & $* * *$ & ns & - & & \\
\hline Triglycerides end-FF ( $g / L)$ & 105 & * & ns & ns & - & $0.85 \pm 0.06^{c}$ & $0.64 \pm 0.07^{d}$ \\
\hline
\end{tabular}

a Least square means of GM diets are given for traits showing an effect of GM diet $(P<0.10)$ and also for traits showing a significant GM effect in the Muscovy duck progeny $(P<0.05)$

"'Magret" is the Pectoralis major with skin of a force-fed duck; FF = Force Feeding

${ }^{* * *} P<0.001 ;{ }^{* *} P<0.01 ;{ }^{*} P<0.05 ;+P<0.10 ;$ ns: not significant; '-interaction not included in the model

$c, d$ Values within a row with different superscripts differ significantly at $P<0.05$

mid-FF. It was significantly higher in the GMMD group $(P<0.05)$. The glucose content at the end of FF showed a trend toward a higher value in the deficient diet group $(3.27 \pm 0.19 \mathrm{~g} / \mathrm{L}$ for the GMMD group vs. $2.83 \pm 0.20 \mathrm{~g} / \mathrm{L}$ for the Control group, $P<0.10$ ).

It is noteworthy that GMMD had no significant effects on several carcass traits: carcass yield, magret weight, and carcass percentage of magret were not altered. Subcutaneous fatness of the whole body, as indicated by the subcutaneous fatness of the magret was not either altered. At last, liver weight, carcass proportion of liver, and technological yield of the liver were not altered.
As tested in a preliminary step, there was no significant interaction between the diet and any other factor of the model, and in particular the sex of the mule duck, indicating that the observed effects were not sex-specific (Additional file 1).

Overall, GMMD effects were significant for several traits, repeated in both years of tests, and were not sexspecific.

Effect of grand-maternal Met-deficiency (GMMD) in G2 purebred Muscovy ducks

Table 3 gives the statistical significance for the factors of the ANOVA and the least square means of G2 Muscovy 

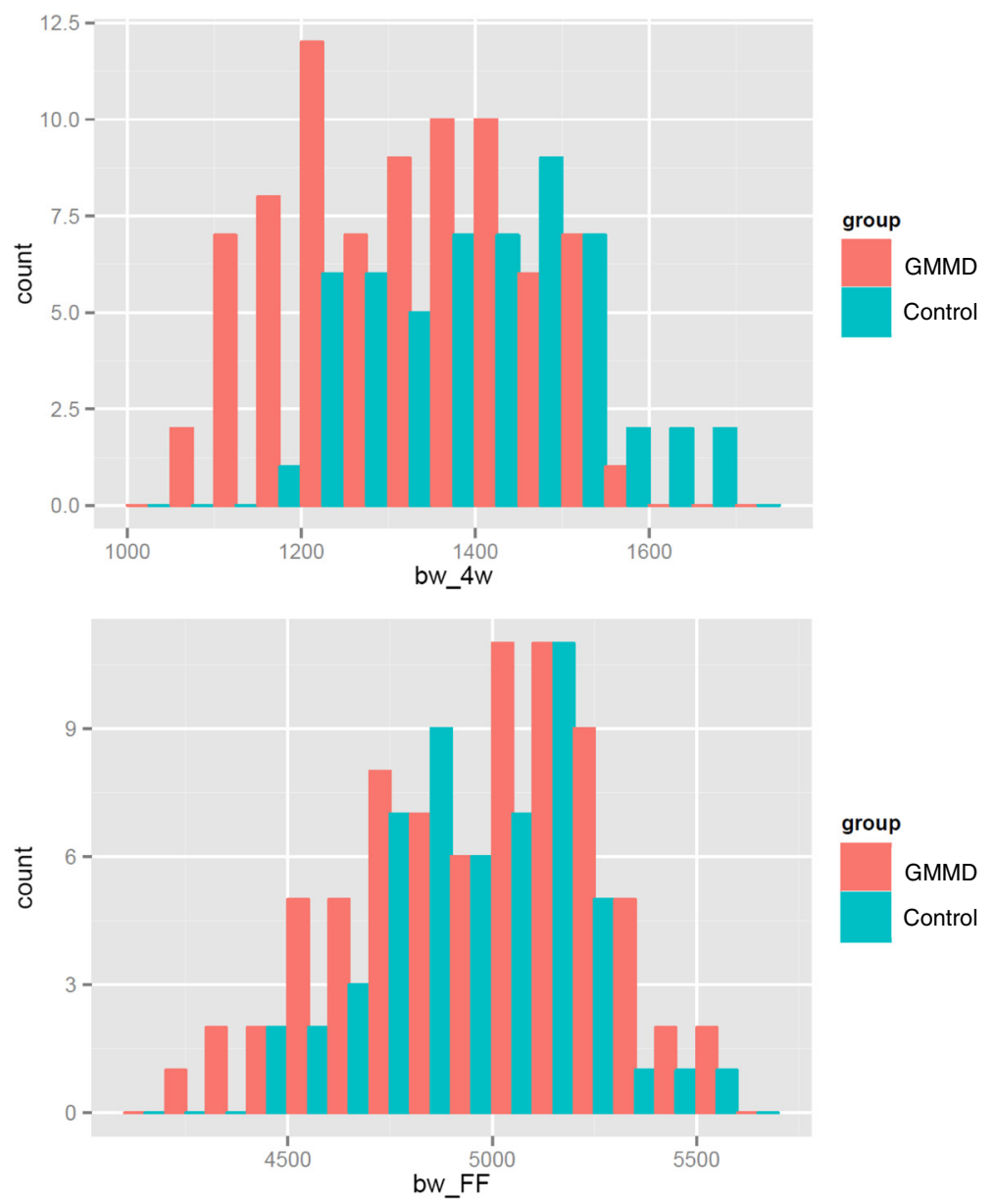

Fig. 2 Body weight differences between control and GMMD groups at two ages, in mule ducks. In G2 mule ducks, the depressive effect of grand-maternal Met restriction on 4weeks-body weight is offset afterward by a positive effect on weight gain until the end of force-feeding. Body weight (g) distribution is shown for GMMD (red) and control (blue) groups. Up : body weight at 4 weeks of age. Down : body weight at 14 weeks of age, at the end of force feeding

duck traits, according to grand-maternal diet (and to grand-maternal diet by sex combination in case of interaction between both factors), for traits showing significant effects in this progeny type (and also for that showing significant effects in the mule progeny, for comparison purpose).

Concerning body weight traits, GMMD tended to decrease 4 and 12 weeks-body weight $(P<0.10)$ and significantly decreased body weight at the end of FF $(P<0.05)$. The effect of GMMD on body weight traits was generally sex-specific, as indicated by trends to interactions between grand-maternal diet and sex, and affected male offspring particularly (Additional file 1). Twelve weeks body weight for example showed a significant interaction $(P<0.0001)$, with no effect on female offspring but a marked effect on male offspring (5269 $\mathrm{g}$ and $5501 \mathrm{~g}$ for the GMMD and Control ducks, respectively). Four to eight weeks weight gain, and eight to 12 weeks weight gain exhibited significant grand-maternal diet by sex interactions (Fig. 3). From four to eight weeks, GMMD males had a higher weight gain than Control ones (difference at $80 \mathrm{~g}, P<0.0001$ ), whereas females showed no differences. From eight to 12 weeks, GMMD males had a lower weight gain than Control ones (difference at $280 \mathrm{~g}, P<0.0001$ ), whereas GMMD females had a higher weight gain than Control ones. Overall, GMMD had a sex-specific effect on weight gain between the ages of 4 and 12 weeks, hampering the growth of male offspring but not that of females. Magret weight was decreased by GMMD, but its proportion in the carcass was not significantly affected. At last, liver weight was higher in GMMD ducks, which had a significantly higher proportion of liver in the carcass.

Whether at mid-FF or at the end of FF, plasmatic glucose content was not affected by grand-maternal diet. By contrast, plasma triglyceride content was influenced by grand-maternal diet at both stages. GMMD increased triglyceride level by $24 \%$ at mid-FF and by $48 \%$ at endFF. The significant interaction between grand-maternal 
Table 3 Results obtained on G2 Muscovy offspring. Statistical significance of the effects of grand-maternal (GM) diet, sex and GM diet by sex interaction on traits of G2 Muscovy offspring, and least square means ( \pm SE) of GM diet ${ }^{a}$, given by sex in case of interaction

\begin{tabular}{|c|c|c|c|c|c|c|}
\hline & $N$ & GM diet & Sex & Diet $x$ sex & Met-deficient & Control \\
\hline \multicolumn{7}{|l|}{ Growth traits } \\
\hline Body weight, 4 weeks & 72 & + & $* * *$ & ns & $1421 \pm 20$ & $1468 \pm 20$ \\
\hline Body weight, 8 weeks & 70 & ns & $* * *$ & ns & $3530 \pm 36$ & $3560 \pm 34$ \\
\hline Body weight, 12 weeks & 72 & + & $* * *$ & * & $4112 \pm 43$ & $4221 \pm 41$ \\
\hline ": males & 37 & & & & $5269 \pm 60^{b}$ & $5501 \pm 59^{a}$ \\
\hline ": females & 35 & & & & $2955 \pm 61$ & $2941 \pm 60$ \\
\hline Weight gain, 4-8weeks & 70 & Ns & $* * *$ & * & & \\
\hline “: males & 36 & & & & $2678 \pm 37^{a}$ & $2596 \pm 36^{b}$ \\
\hline “: females & 34 & & & & $1525 \pm 38$ & $1589 \pm 37$ \\
\hline Weight gain, 8-12weeks & 70 & * & $* * *$ & $* * *$ & $574 \pm 34^{b}$ & $660 \pm 32^{\mathrm{a}}$ \\
\hline ": males & 36 & & & & $921 \pm 50^{b}$ & $1202 \pm 49^{a}$ \\
\hline ": females & 34 & & & & $227 \pm 51^{\mathrm{a}}$ & $119 \pm 50 b$ \\
\hline Weight gain, 4-12weeks & 72 & Ns & $* * * *$ & * & & \\
\hline “: males & 37 & & & & $3609 \pm 55^{b}$ & $3798 \pm 54^{\mathrm{a}}$ \\
\hline ": females & 35 & & & & $1772 \pm 57$ & $1708 \pm 55$ \\
\hline \multicolumn{7}{|l|}{ Force-feeding (FF) traits } \\
\hline Weight gain during FF & 70 & ns & $* * *$ & ns & $1132 \pm 30$ & $1153 \pm 30$ \\
\hline Body weight, 14 weeks (end FF) & 70 & * & $* * *$ & ns & $5244 \pm 51^{b}$ & $5390 \pm 51^{a}$ \\
\hline \multicolumn{7}{|l|}{ Carcass traits } \\
\hline Carcass weight (CW) & 71 & * & $* * *$ & ns & & \\
\hline Magret $^{\mathrm{b}}$ weight & 71 & ns & $* * *$ & ns & $437 \pm 5^{\mathrm{b}}$ & $452 \pm 5^{\mathrm{a}}$ \\
\hline Ratio (magret/carcass) & 71 & ns & * & ns & & \\
\hline Magret muscle weight & 71 & ns & $* * *$ & ns & & \\
\hline Ratio (fat + skin/magret) & 71 & ns & ns & ns & & \\
\hline Abdominal fat weight (AF) & 71 & ns & $* * *$ & ns & $154 \pm 5$ & $154 \pm 5$ \\
\hline Ratio AF/CW \% & 71 & & $* *$ & ns & $3.29 \pm 0.10$ & $3.18 \pm 0.10$ \\
\hline Liver weight (LW) & 71 & + & $* * *$ & ns & $479 \pm 12$ & $451 \pm 12$ \\
\hline Ratio (LW/CW) & 71 & $*$ & $* * *$ & ns & $10.3 \pm 0.2^{a}$ & $9.6 \pm 0.2^{b}$ \\
\hline Blood metabolites & 71 & & & & & \\
\hline Glucose mid-FF (g/L) & 71 & ns & ns & ns & & \\
\hline Glucose end-FF (g/L) & 71 & ns & * & ns & & \\
\hline Triglycerides mid-FF (g/L) & 71 & $* *$ & $* * *$ & $* *$ & $0.41 \pm 0.02^{\mathrm{a}}$ & $0.33 \pm 0.02^{b}$ \\
\hline “: males & 37 & & & & $0.32 \pm 0.02$ & $0.31 \pm 0.02$ \\
\hline ": females & 34 & & & & $0.50 \pm 0.02^{\mathrm{a}}$ & $0.35 \pm 0.02^{\mathrm{b}}$ \\
\hline Triglycerides end-FF (g/L) & 70 & * & + & ns & $0.59 \pm 0.06^{\mathrm{a}}$ & $0.40 \pm 0.06^{b}$ \\
\hline
\end{tabular}

aLeast square means of GM diets are given for traits showing an effect of GM diet $(P<0.10)$ and also for traits showing a significant GM effect in the mule duck progeny $(P<0.05)$

"Magret" is the Pectoralis major with skin of a force-fed duck; FF = Force Feding

${ }^{* * *} P<0.001 ;{ }^{* *} P<0.01 ;{ }^{*} P<0.05 ;+P<0.10 ;$ ns: not significant. ${ }^{\mathrm{a}, \mathrm{b}}$ Values within a row with different superscripts differ significantly at $P<0.05$

diet and sex at mid-FF reflected that only the females were affected. The pattern was the same at the end of FF, although not significantly, due to the large standarddeviation of triglyceride content at that stage: no differences between GMMD and Control males (0.46 \pm $0.08 \mathrm{~g} / \mathrm{L}$ and $0.38 \pm 0.08 \mathrm{~g} / \mathrm{L}$ for GMMD and Control males, respectively) but a difference between GMMD and Control females $(0.71 \pm 0.08 \mathrm{~g} / \mathrm{L}$ and $0.42 \pm 0.08 \mathrm{~g} / \mathrm{L}$ for 

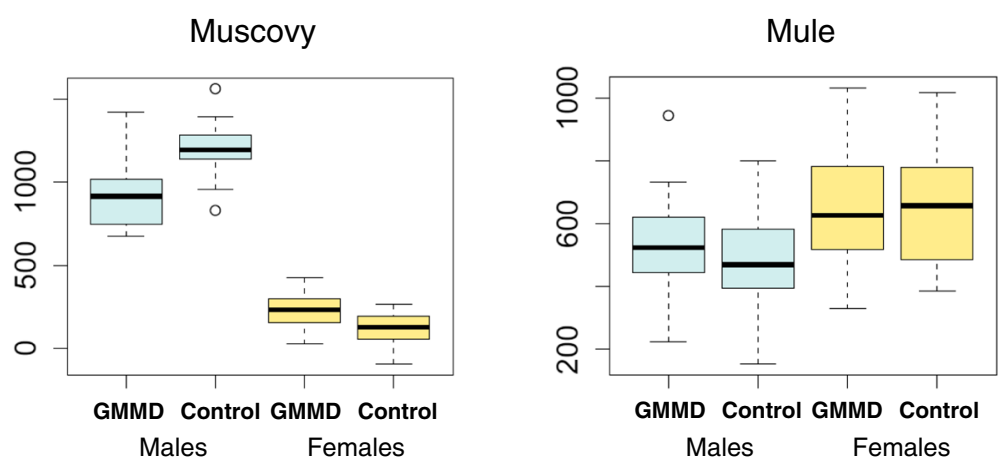

Fig. 3 Differences in weight gain (8-12 weeks) between control and GMMD groups according to the sex. Boxplots show the interaction diet $x$ sex in Muscovy ducks (left)

GMMD and Control females, respectively). Thus, GMMD had a sex-specific effect on triglyceride content, which was limited to the females.

As for the mule ducks, GMMD effects were significant for several traits in G2 purebred Muscovy ducks, being sex-specific in many cases.

\section{Discussion}

By measuring several production and metabolic traits in purebred Muscovy or hybrid mule ducks of which the paternal grand-mother was fed a methionine-restricted diet, we showed that the mother diet is able to affect the offspring of her sons. The transmission of such effects over two generations through the father was observed in both genetic types for traits such as body weight before force-feeding and triglycerides plasma concentration, while other traits affected by the grand-mother diet were genetic type-specific.

\section{GMMD effects in mule ducks vs. Muscovy ducks}

The effects observed at G2 in mule ducks and in Muscovy ducks share common features: in both genetic types, GMMD decreased body weights during the growth phase from 4 to 12 weeks of age. In the purebred Muscovy ducks, this effect was however limited to the male progeny. A year effect was observed in G2 mule ducks, and particularly a sex by year interaction on liver-related traits. This year effect is likely to be multifactorial since factors influencing these zootechnical traits are numerous, including incubation conditions, temperature and hygrometry during the growth phase, and forcefeeding conditions.

Surprisingly, some effects of GMMD were specific of the genetic type of the G2 offspring. The marked effect of GMMD on weight gain during force-feeding and on abdominal fat weight was observed in the mule duck progeny only. The effects of GMMD on magret weight and on carcass proportion of fatty liver were specific of the purebred Muscovy progeny.
The hybrid mule duck progeny and the purebred Muscovy progeny have thus specific responses to GMMD, particularly for growth traits (sex-specific response in Muscovy ducks only) and for FF traits (weight gain during FF in mule ducks only and specific localization of fat deposits).

The sex-specific effects on growth in Muscovy ducks may be linked to the sexual dimorphism of body weight which is particularly marked in this species, as compared to the common duck or to the mule duck [18]. This sexual dimorphism clearly appeared in our study, as for example in the control group: the 12 weeks body weight was $5501 \mathrm{~g}$ in males vs. $2941 \mathrm{~g}$ in females. The nutritional requirements of males and females are therefore very different, and the fact that GMMD affected particularly weight gain between the ages of 8 and 12 weeks, including the phase of preparation to FF with limited time for feed consumption, could involve sex-specific response group to nutritional restriction. Several studies have shown environmental sex-specific effects, including epigenetics modifications, during embryogenesis (see [19] for a review).

\section{Grand-maternal Met restriction affected traits associated with lipid metabolism}

In contrast with the depressive effect on body weight, GMMD increased traits associated with lipid metabolism such as weight gain during FF and abdominal fat weight in the mule duck progeny, and the carcass proportion of fatty liver in the Muscovy duck progeny. Thus, the diet seems to drive the localization of fat deposits towards abdominal fat in mule ducks, and towards liver in Muscovy ducks. This seems to reinforce the natural differences between these two genetic backgrounds, already observed [20-22]. In birds, the liver is the principal site of lipogenesis, which, in the case of force-feeding, consists of the synthesis of triglycerides from glucose, resulting itself from the digestion of the starch of the feed. In the liver, the unbalance between lipogenesis and lipid exportation 
leads to liver steatosis. The exported triglycerides are transported as VLDL (Very Low Density Lipoproteins) to peripheral tissues, forming subcutaneous, abdominal, and intra-muscular fat deposits. During FF, most of the body weight gain is made of lipids, not excluding the continuation of muscular growth. Liver weight is a good indicator of liver fat content, since lipids represent $61 \%$ of fatty liver weight [22] and since the correlation between liver weight and liver fat content was found to be 0.95 in a population of mule ducks (X Fernandez, personal communication).

Beyond the lipid synthesis, Met restriction of the grand-mother influenced the body distribution of the triglyceride storage from lipogenesis. Indeed, in the mule duck progeny, abdominal fat weight was altered, but neither was the liver weight nor the subcutaneous fatness of the body after force-feeding. In the Muscovy duck progeny, the body distribution of the triglycerides storage was also altered by GMMD: the ducks from Met-restricted grand-mothers retained more triglycerides in the liver, at the expense of subcutaneous fatness which was decreased, however not significantly. Indeed, the indicator of the overall body subcutaneous fatness, the magret percentage of (skin + fat) was $9.07 \pm 0.08 \%$ in the Met-restricted group vs. $9.21 \pm 0.08 \%$ in the Control one.

Our data could be viewed in relation with what is observed in mammals where several studies showed that methyl donor deficient diets (MDD diets) affect hepatic metabolism in F0 and/or F1 generations. In rodents for example, Methionine and Choline deficiency favors hepatic steatosis [23, 24], through increased fatty acid uptake and decreased VLDL secretion by the liver [25]. In rats, maternal MDD diet induces hepatic steatosis [26] and changes in liver proteome [27]. In sheep, maternal MDD diet affects the gene methylation level in the liver of F1 offspring [28]. Epigenetic changes have been evoked to explain these effects since methyl donors such as folate, choline, methionine and vitamins B6 and B12, are involved in one-carbon metabolism which releases methyl groups $(-\mathrm{CH} 3)$ used by methyltransferases to methylate DNA and histone proteins (see [29-31] for reviews). Furthermore, the deficiency of methyl groups may affect the transmethylation of co-regulators of nuclear receptors such as PGC1- $\alpha$ which is a master regulator of lipid metabolism and fatty acid oxidation $[26,29,30]$. More recently, Chen and coworkers identified modifications of DNA methylation in the promoter regions of 1032 genes in liver of $\mathrm{F} 1$ offspring from female rats fed with MMD diet [32]. To our knowledge, no such maternal MDD diet studies have been carried out in birds, and our work differs from the ones cited above in the fact that it focuses on the F2 generation and that the non genetic effects of the MMD diet are transmitted through the sons, and thus through their spermatozoa, to the F2 generation.
Such effects of female diet transmitted to their grandchildren via their sons have already been reported in humans. Thus studying a cohort of grandchildren of women exposed to 1944-45 Duch famine, Veenendaal and coworkers reported that adult offspring (F2) of prenatally exposed F1 fathers were heavier and more obese than children of fathers who had not been prenatally exposed [9].

\section{Epigenetic vs genetic effects}

It cannot be excluded that part of the differences observed in G2 between the two grand-maternal diet groups, in both the mule duck and the purebred Muscovy progenies, can have a genetic origin. Sampling bias can have occurred in G0, due to the small number of founders, resulting in genetic differences between the two groups of founders. Again, the small number of G1 drakes may add some genetic drift, responsible for an additional error in the G2 progeny mean estimation [33]. Our tests for comparing met-deficient and control G2 offspring did not take the genetic drift into account, but the absence of differences in the average weights of the two groups of G1 males brings some reassurance concerning this putative bias. But the results observed are compatible with the existence of epigenetic effects. Indeed, it is now well documented in mammals that environmental exposures (e.g., toxins, stress or nutritional deprivation) of the G0 generation can influence gene regulations and the adult phenotypes of the G1, G2 ("multigenerational") and G3 generations ("transgenerational") through epigenetic mechanisms (e.g., DNA methylation, histone modifications or miRNA) [8, 34-38]. In birds, resources deposited in the egg (e.g., nutrients, hormones, carotenoids, vitamins or RNA transcripts) can also impact newborn fitness and later adult phenotypes of the G1 generation. But the egg composition can also directly affect the G2 generation since the developing G1 generation bears the primordial germ cells that will eventually form a G2 progeny. Hence, the maternal nutritional deficiency may have affected the epigenetic information carried by the G1 drake spermatozoa, as already reported in mammals [39]. This non-genetic inheritance may be partially involved in human metabolic diseases [40]. Epigenetics marks in the Primordial Germ Cells of the developing father may be influenced by the environment of his mother [7]. This transmission of information through the paternal germline may involve modifications of chromatin, small RNAs, or other mechanisms, yet to be deciphered [41, 42].

Contrary to maternal effects [43], paternal effects have received much less attention [44, 45]. Nevertheless, several studies have shown that the father may transmit non-genetic information through spermatozoa epigenetic marks [39, 46, 47], or sperm component factors [48]. As the father's environment modification happened 
during the father's embryonic development in our study, we hypothesize that epigenetic effects may be involved in the results observed here.

\section{Conclusions}

Our results indicate that the females' diets can affect their grand-offspring through their sons, in the Muscovy duck. This was observed in two genetic backgrounds (hybrids and purebreds) for traits such as body weight before force-feeding and triglycerides plasma concentration after force-feeding, whereas other traits affected by the grand-mother's diet were genetic backgroundspecific, such as the weight gain during force-feeding or the localization of lipid deposition. Whether this transmission through the father of information induced in the grand-mother by the environment is epigenetic remains to be demonstrated.

\section{Availability of supporting data}

The data sets supporting the results of this article are included as Additional file 2.

\section{Additional files}

Additional file 1: Results obtained on G2 offspring by genetic type, sex and grand-maternal diet. (DOCX $41 \mathrm{~kb}$ )

Additional file 2: Supporting data. (TXT $27 \mathrm{~kb}$ )

\section{Abbreviations}

FF: Force feeding; GMMD: Grand-maternal met-deficiency; VLDL: Very low density lipoproteins.

\section{Competing interests}

The authors declare that they have no competing interests.

\begin{abstract}
Authors' contributions
$J M B, M M$ and FP conceived, designed and coordinated the study. JMB performed the statistical analyses. JMB and FP drafted the manuscript. MDB $A C, B B$ and $X M$ managed the animals' production. ML and NS formulated the experimental diets and supervised the making of the diets. SL, SD, MJ and MM managed the sampling and performed experimental analyses. SD, $L B, M M, J M B$ and FP contributed to the interpretation of the results and to the writing of the manuscript. All authors read and approved the final manuscript.
\end{abstract}

\section{Acknowledgements}

The authors thank the entire staff of the UEPFG and PEAT experimental units, and the French National Research Agency (ANR) for its EpiBird grant (ANR-09-GENM-004, http://www.agence-nationale-recherche.fr/) and AGENAVI, which granted the 2013 extension of the experiment.

\section{Author details}

'UMR INRA, Génétique, Physiologie et Systèmes d'Elevage, INRA, 31328 Castanet Tolosan, France. ${ }^{2}$ INPT ENSAT, Génétique, Physiologie et Systèmes d'Elevage, INRA, 31328 Castanet Tolosan, France. ${ }^{3}$ INPT ENVT, Génétique, Physiologie et Systèmes d'Elevage, INRA, 31328 Castanet Tolosan, France. ${ }^{4}$ Institut National de la Recherche Agronomique, Unité Expérimentale des Palmipèdes à Foie Gras, UE89, 40280 Benquet, France. ${ }^{5}$ UMR5254 IUT des Pays de I'Adour-CNRS, 40004 Mont de Marsan Cedex, France. ${ }^{6}$ Institut National de la Recherche Agronomique, UR83 Unité de Recherche Avicole, 37380 Nouzilly, France. ${ }^{7}$ Institut National de la Recherche Agronomique, Pôle d'Expérimentation Avicole de Tours, UE1295, 37380 Nouzilly, France. ${ }^{8}$ Present addresses: ITSAP-Institut de I'Abeille, Site Agroparc, 84914 Avignon, France. ${ }^{9}$ UMT Protection des Abeilles dans l'Environnement, CS 40506, 84914 Avignon, France.

Received: 6 July 2015 Accepted: 10 December 2015

Published online: 21 December 2015

\section{References}

1. Dickerson GE. Experimental approaches in utilizing breed resources. Anim Breed Abstr. 1969;37:191-202.

2. Willham RL. The role of maternal effects in animal breeding. 3. Biometrical aspects of maternal effects in animals. J Anim Sci. 1972;35(6):1288-93.

3. Jablonka E, Lamb MJ. Epigenetic inheritance and evolution: The Lamarckian Dimension. Oxford, UK: Oxford University Press; 1995

4. Jablonka E, Raz G. Transgenerational epigenetic inheritance: prevalence, mechanisms, and implications for the study of heredity and evolution. Q Rev Biol. 2009:84(2):131-76.

5. Anderson LM, Riffle L, Wilson R, Travlos GS, Lubomirski MS, Alvord WG. Preconceptional fasting of fathers alters serum glucose in offspring of mice. Nutrition. 2006;22(3):327-31. doi:10.1016/j.nut.2005.09.006.

6. Ng SF, Lin RC, Laybutt DR, Barres R, Owens JA, Morris MJ. Chronic high-fat diet in fathers programs beta-cell dysfunction in female rat offspring. Nature. 2010;467(7318):963-6. doi:10.1038/nature09491.

7. Soubry A, Hoyo C, Jirtle RL, Murphy SK. A paternal environmental legacy: evidence for epigenetic inheritance through the male germ line. Bioessays. 2014:36(4):359-71. doi:10.1002/bies.201300113.

8. Szyf M. Nongenetic inheritance and transgenerational epigenetics. Trends Mol Med. 2015;21(2):134-44. doi:10.1016/j.molmed.2014.12.004.

9. Veenendaal MV, Painter RC, de Rooij SR, Bossuyt PM, van der Post JA, Gluckman PD, et al. Transgenerational effects of prenatal exposure to the 1944-45 Dutch famine. BJOG. 2013;120(5):548-53. doi:10.1111/14710528.12136

10. Kaati G, Bygren LO, Edvinsson S. Cardiovascular and diabetes mortality determined by nutrition during parents' and grandparents' slow growth period. Eur J Hum Genet. 2002;10(11):682-8. doi:10.1038/sj.ejhg.5200859.

11. Pembrey ME, Bygren LO, Kaati G, Edvinsson S, Northstone K, Sjostrom M, et al. Sex-specific, male-line transgenerational responses in humans. Eur J Hum Genet. 2006;14(2):159-66. doi:10.1038/sj.ejhg.5201538.

12. Bygren LO, Tinghog P, Carstensen J, Edvinsson S, Kaati G, Pembrey ME, et al. Change in paternal grandmothers' early food supply influenced cardiovascular mortality of the female grandchildren. BMC Genet. 2014;15: 12. doi:10.1186/1471-2156-15-12.

13. Anway MD, Cupp AS, Uzumcu M, Skinner MK. Epigenetic transgenerational actions of endocrine disruptors and male fertility. Science. 2005;308(5727): 1466-9. doi:10.1126/science.1108190.

14. Fresard L, Morisson M, Brun JM, Collin A, Pain B, Minvielle F, et al. Epigenetics and phenotypic variability: some interesting insights from birds. Genet Sel Evol. 2013:45:16. doi:10.1186/1297-9686-45-16.

15. Yazbek SN, Spiezio SH, Nadeau JH, Buchner DA. Ancestral paternal genotype controls body weight and food intake for multiple generations. Hum Mol Genet. 2010;19(21):4134-44. doi:10.1093/hmg/ddq332.

16. Gluckman PD, Hanson MA, Beedle AS. Non-genomic transgenerational inheritance of disease risk. Bioessays. 2007;29(2):145-54. doi:10.1002/bies. 20522.

17. Marie-Etancelin C, Basso B, Davail S, Gontier K, Fernandez X, Vitezica ZG, et al. Genetic parameters of product quality and hepatic metabolism in fattened mule ducks. J Anim Sci. 2011;89(3):669-79. doi:10.2527/jas.2010-3091.

18. Brun J-M, Richard MM, Marie Etancelin C, Rouvier R, Larzul C. Le canard mulard : déterminisme génétique d'un hybride intergénérique. Prod Anim. 2005;18(5):295-308.

19. Laguna-Barraza R, Bermejo-Alvarez $P$, Ramos-lbeas $P$, de Frutos $C$, Lopez-Cardona AP, Calle A, et al. Sex-specific embryonic origin of postnatal phenotypic variability. Reprod Fertil Dev. 2012;25(1):38-47. doi:10.1071/RD12262

20. Davail S, Rideau N, Guy G, Andre JM, Hermier D, Hoo-Paris R. Hormonal and metabolic responses to overfeeding in three genotypes of ducks. Comp Biochem Physiol A Mol Integr Physiol. 2003;134(4):707-15.

21. Gontier K, Andre JM, Bernadet MD, Ricaud K, Davail S. Insulin effect on lipogenesis and fat distribution in three genotypes of ducks during overfeeding. Comp Biochem Physiol A Mol Integr Physiol. 2013;164(3):499-505. doi:10.1016/j.cbpa.2012.12.019 
22. Salichon MR, Guy G, Rousselot-Pailley D, Blum JC. Composition des 3 types de foie gras : oie, canard, mulard et canard de Barbarie. Ann Zootech. 1994:43(2):213-20.

23. Stankovic MN, Mladenovic D, Ninkovic M, Ethuricic I, Sobajic S, Jorgacevic B, et al. The effects of alpha-lipoic acid on liver oxidative stress and free fatty acid composition in methionine-choline deficient diet-induced NAFLD. J Med Food. 2014;17(2):254-61. doi:10.1089/jmf.2013.0111.

24. Weltman MD, Farrell GC, Liddle C. Increased hepatocyte CYP2E1 expression in a rat nutritional model of hepatic steatosis with inflammation. Gastroenterology. 1996;111(6):1645-53.

25. Rinella ME, Elias MS, Smolak RR, Fu T, Borensztajn J, Green RM. Mechanisms of hepatic steatosis in mice fed a lipogenic methionine choline-deficient diet. J Lipid Res. 2008;49(5):1068-76. doi:10.1194/jlr.M800042-JLR200.

26. Pooya S, Blaise S, Moreno Garcia M, Giudicelli J, Alberto JM, GueantRodriguez RM, et al. Methyl donor deficiency impairs fatty acid oxidation through PGC-1alpha hypomethylation and decreased ER-alpha, ERR-alpha, and HNF-4alpha in the rat liver. J Hepatol. 2012;57(2):344-51. doi:10.1016/j. jhep.2012.03.028

27. Maloney CA, Hay SM, Reid MD, Duncan G, Nicol F, Sinclair KD, et al. A methyl-deficient diet fed to rats during the pre- and peri-conception periods of development modifies the hepatic proteome in the adult offspring. Genes Nutr. 2013;8(2):181-90. doi:10.1007/s12263-012-0314-6.

28. Sinclair KD, Allegrucci C, Singh R, Gardner DS, Sebastian S, Bispham J, et al. DNA methylation, insulin resistance, and blood pressure in offspring determined by maternal periconceptional B vitamin and methionine status. Proc Natl Acad Sci U S A. 2007;104(49):19351-6. doi:10.1073/pnas. 0707258104.

29. Gueant JL, Elakoum R, Ziegler O, Coelho D, Feigerlova E, Daval JL, et al. Nutritional models of foetal programming and nutrigenomic and epigenomic dysregulations of fatty acid metabolism in the liver and heart. Pflugers Arch. 2014;466(5):833-50. doi:10.1007/s00424-013-1339-4.

30. Gueant JL, Namour F, Gueant-Rodriguez RM, Daval JL. Folate and fetal programming: a play in epigenomics? Trends Endocrinol Metab. 2013;24(6):279-89. doi:10.1016/j.tem.2013.01.010.

31. Vickers $\mathrm{MH}$. Early life nutrition, epigenetics and programming of later life disease. Nutrients. 2014;6(6):2165-78. doi:10.3390/nu6062165.

32. Chen G, Broseus J, Hergalant S, Donnart A, Chevalier C, Bolanos-Jimenez F, et al. Identification of master genes involved in liver key functions through transcriptomics and epigenomics of methyl donor deficiency in rat: relevance to nonalcoholic liver disease. Mol Nutr Food Res. 2015;59(2):293-302. doi:10.1002/mnfr.201400483.

33. Nicholas FW. Size of population required for artificial selection. Genet Res. 1980;35(1):85-105.

34. Cedar H, Bergman Y. Programming of DNA methylation patterns. Annu Rev Biochem. 2012:81:97-117. doi:10.1146/annurev-biochem-052610-091920.

35. Feil R, Fraga MF. Epigenetics and the environment: emerging patterns and implications. Nat Rev Genet. 2011;13(2):97-109. doi:10.1038/nrg3142.

36. Jammes $\mathrm{H}$, Junien $\mathrm{C}$, Chavatte-Palmer P. Epigenetic control of development and expression of quantitative traits. Reprod Fertil Dev. 2011:23(1):64-74. doi:10.1071/RD10259.

37. Skinner MK. Environmental epigenetic transgenerational inheritance and somatic epigenetic mitotic stability. Epigenetics. 2011;6(7):838-42.

38. Skinner MK, Guerrero-Bosagna C, Haque M, Nilsson E, Bhandari R, McCarrey JR. Environmentally induced transgenerational epigenetic reprogramming of primordial germ cells and the subsequent germ line. PLoS One. 2013;8(7), e66318. doi:10.1371/journal.pone.0066318.

39. Daxinger $L$, Whitelaw $E$. Understanding transgenerational epigenetic inheritance via the gametes in mammals. Nat Rev Genet. 2012;13(3):153-62. doi:10.1038/nrg3188.

40. Stegemann R, Buchner DA. Transgenerational inheritance of metabolic disease. Semin Cell Dev Biol. 2015. doi:10.1016/j.semcdb.2015.04.007.

41. Heard E, Martienssen RA. Transgenerational epigenetic inheritance: myths and mechanisms. Cell. 2014;157(1):95-109. doi:10.1016/j.cell.2014.02.045.

42. Feng $L$, Chen $X$. Epigenetic regulation of germ cells-remember or forget? Curr Opin Genet Dev. 2015;31:20-7. doi:10.1016/j.gde.2015.04.003.

43. Falconer, DS, Mackay TFC. Introduction to Quantitative Genetics, 4th edition. Longmans Green, Harlow, Essex, UK.; 1996

44. Crean AJ, Bonduriansky R. What is a paternal effect? Trends Ecol Evol. 2014;29(10):554-9. doi:10.1016/j.tree.2014.07.009.
45. Soubry A. Epigenetic inheritance and evolution: A paternal perspective on dietary influences. Prog Biophys Mol Biol. 2015;118(1-2):79-85. doi:10.1016/j. pbiomolbio.2015.02.008

46. Marczylo EL, Amoako AA, Konje JC, Gant TW, Marczylo TH. Smoking induces differential miRNA expression in human spermatozoa: a potential transgenerational epigenetic concern? Epigenetics. 2012;7(5):432-9. doi:10.4161/epi.19794

47. Marshall DJ. Environmentally induced (co)variance in sperm and offspring phenotypes as a source of epigenetic effects. J Exp Biol. 2015;218(Pt 1):107-13. doi:10.1242/jeb.106427.

48. Wong $\mathrm{CL}$, Lee $\mathrm{KH}$, Lo KM, Chan OC, Goggins W, WS O, et al. Ablation of paternal accessory sex glands imparts physical and behavioural abnormalities to the progeny: an in vivo study in the golden hamster. Theriogenology. 2007;68(4):654-62. doi:10.1016/j.theriogenology.2007.04.062.

\section{Submit your next manuscript to BioMed Central and we will help you at every step:}

- We accept pre-submission inquiries

- Our selector tool helps you to find the most relevant journal

- We provide round the clock customer support

- Convenient online submission

- Thorough peer review

- Inclusion in PubMed and all major indexing services

- Maximum visibility for your research

Submit your manuscript at www.biomedcentral.com/submit
) Biomed Central 